\title{
Atractylenolide-1 alleviates gastroparesis in diabetic rats by activating the stem cell factor/c-kit signaling pathway
}

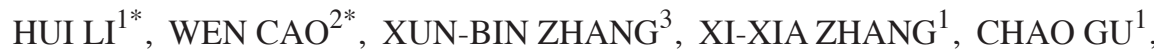 \\ LI-MEI GU ${ }^{1}$, CHENG-YU PAN ${ }^{1}$, YAO-ZHOU TIAN ${ }^{1,4^{* *}}$ and MIN LU ${ }^{3 * *}$
}

\begin{abstract}
Departments of ${ }^{1}$ Gastroenterology and ${ }^{2}$ Endocrinology, Affiliated Hospital of Integrated Traditional Chinese and Western Medicine, Nanjing University of Chinese Medicine, Nanjing, Jiangsu 210028;

${ }^{3}$ Department of Gastroenterology, Nanjing Lishui District Hospital of Traditional Chinese Medicine, Nanjing, Jiangsu 211200;

${ }^{4}$ Department of Pharmacology, Nanjing Medical University, Nanjing, Jiangsu 210011, P.R. China
\end{abstract}

Received September 2, 2020; Accepted June 7, 2021

DOI: $10.3892 / \mathrm{mmr} .2021 .12331$

\begin{abstract}
Diabetic gastroparesis (DGP), also known as delayed gastric emptying, is a common complication of diabetes mellitus. There are numerous clinical symptoms associated with DGP, as well as high treatment costs and markedly reduced patient quality of life. However, the pathogenesis of DGP is not clear, thus effective treatment methods are yet to be established. In the present study, a DGP rat model was established in Sprague-Dawley rats by the intraperitoneal injection of streptozotocin (STZ). DGP model rats were treated with different doses of atractylenolide-1 to detect alterations in gastrointestinal function, including gastroparesis, gastric emptying, gastric motility, gastric peristalsis and gastric blood flow. Compared with the DGP group, atractylenolide-1 treatment significantly reduced glycaemia and the level of glycated hemoglobin, as well as restoring gastrointestinal function. Gastroparesis, gastric emptying, gastric motility, gastric peristalsis and gastric blood flow were significantly impaired in the STZ-induced group compared with the vehicle control group. Moreover, the STZ-induced group displayed downregulated expression levels of the DGP indicator KIT proto-oncogene, receptor tyrosine kinase (c-kit),
\end{abstract}

Correspondence to: Dr Yao-Zhou Tian, Department of Gastroenterology, Affiliated Hospital of Integrated Traditional Chinese and Western Medicine, Nanjing University of Chinese Medicine, 100 Shizi Street, Nanjing, Jiangsu 210028, P.R. China E-mail: yaozhou_tian@163.com

Dr Min Lu, Department of Gastroenterology, Nanjing Lishui District Hospital of Traditional Chinese Medicine, 201 Wenchang Road, Lishui, Nanjing, Jiangsu 211200, P.R. China

E-mail: 666xlsr@sina.com

\section{${ }^{* * * *}$ Contributed equally}

Key words: diabetic gastroparesis, atractylenolide-1, interstitial cells of Cajal, stem cell factor/KIT proto-oncogene, receptor tyrosine kinase signaling pathway, apoptosis, oxidative stress as investigated by immunohistochemistry, and stem cell factor (SCF) protein, as assessed using ELISA, significantly enhanced rat interstitial cells of Cajal (ICC) apoptosis, and significantly altered levels of oxidative stress-related markers (malondialdehyde and superoxide dismutase) in the serum and gastric tissues compared with the vehicle control group. By contrast, treatment with atractylenolide-1 significantly counteracted the effects of DGP on peristalsis, inhibited apoptosis and suppressed oxidative stress by regulating the expression of heme oxygenase 1 in STZ-induced DGP model rats. Further research indicated that atractylenolide-1 regulated oxidative stress reactions and improved gastric function by activating the SCF/c-kit signaling pathway. Collectively, the results of the present study suggested that atractylenolide-1 promoted ICC survival and preserved the structure of the gastric tissue network in a DGP rat model via the SCF/c-kit signaling pathway, providing novel insights for the treatment of DGP.

\section{Introduction}

Diabetic gastroparesis (DGP) is a common complication of diabetes mellitus, affecting $50-60 \%$ of patients with type 1 diabetes mellitus $(1,2)$ and $30-40 \%$ of patients with type 2 diabetes mellitus (3). DGP is defined as delayed gastric emptying without evidence of mechanical obstruction $(4,5)$. The primary clinical symptoms of DGP include manifestations of gastric neuromuscular dysfunction, such as satiety, weight loss, abdominal distension and pain, discomfort, nausea and vomiting $(6,7)$. Therefore, treatments for DGP aim to correct nutritional status by improving gastric emptying, repairing gastric injury and restoring gastrointestinal function. In addition, DGP induces malnutrition, serious environmental disorders in the body, multiple organ dysfunction and even systemic organ failure, considerably impacting patient quality of life and resulting in a heavy economic burden (8). The challenge with clinical treatment is that the majority of current DGP therapies are ineffective and are associated with several adverse reactions, leading to oral malnutrition and increased hospitalization frequency $(9,10)$.

Previous studies on DGP have focused on hyperglycemia, autonomic neuropathy and interstitial cells of Cajal (ICCs) (11), 
which are key factors that influence gastric movement and emptying by regulating gastrointestinal pacing $(12,13)$. Such studies have provided a theoretical basis for the treatment of DGP. ICCs are pacemaker cells of gastrointestinal motility that serve an important role in the regulation of gastric emptying and the maintenance of normal gastric function (14-19).

KIT proto-oncogene, receptor tyrosine kinase (c-kit) is a transmembrane tyrosine kinase receptor expressed by ICCs. Normal expression of the c-kit proteins requires the maintenance of normal signaling pathways that regulate gastric contraction (15). Furthermore, previous studies have shown that stem cell factor (SCF) protein can increase the number of ICCs, enhance gastrointestinal motility and repair ICC structural lesions $(20,21)$.

Atractylodes macrocephala Koidz (A. macrocephala) has been used for both the Traditional Chinese and modern clinical treatment of gastrointestinal diseases (22). Previous in vivo studies have revealed that atractylenolide-1, one of the primary bioactive compounds of A. macrocephala, has the ability to repair the gastrointestinal mucosa of mice $(23,24)$. Atractylenolide-1 has also been reported to significantly improve the clinical symptoms of patients with DGP, but the mechanisms underlying the improvement in gastrointestinal function remain unclear $(23,25,26)$. The aim of the present study was to reveal the potential of atractylenolide- 1 for treating gastroparesis and improve the current understanding of the molecular mechanisms underlying atractylenolide- 1 in DGP, providing novel insights for DGP therapy. The effective components of atractylenolide- 1 will be the focus of subsequent studies, with an aim to achieve a more in-depth understanding of their therapeutic effects.

\section{Materials and methods}

Animal models. All experiments used in the present study were approved by the Institutional Animal Ethics Committee of the Nanjing Medical University (approval no. IACUC-1703031) and were performed in accordance with the International Standards and the Ethical Guidelines on Animal Welfare (National Research Council, 1996 and Canadian Council on Animal Care, 1993) (27,28). All animals were euthanized using ethically approved methods and every effort was made to minimize discomfort and pain.

A total of 60 male Sprague-Dawley rats (weight, $200 \mathrm{~g}$; age, 6 weeks) were obtained from Shanghai SLAC Laboratory Animal Co., Ltd. The rats were maintained in a controlled environment $\left(22 \pm 2^{\circ} \mathrm{C}\right.$, relative humidity $\left.40-70 \%\right)$ with 12 -h light/dark cycles, and ad libitum access to food and water. Rats were allowed to adapt for 1 week prior to study commencement. For the normal control (NC) group, 12 randomly selected rats were fed a basal diet and simultaneously injected (intraperitoneal) $0.1 \mathrm{~mol} / 1$ sodium citrate buffer $(\mathrm{pH} 4.0)$. The remaining 48 rats were treated with a single daily intraperitoneal injection of freshly prepared $0.5 \%$ streptozotocin (STZ) solution ( $60 \mathrm{mg} / \mathrm{kg}$; Sigma-Aldrich; Merck KGaA) in $0.1 \mathrm{~mol} / \mathrm{l}$ citrate buffer ( $\mathrm{pH} 4.0$ ). After 7 days of treatment, blood samples were drawn from the caudal vein and blood glucose levels were measured using an Accu-Chek Advantage blood glucose meter and test strip (Roche Diagnostics); a blood glucose concentration $>350 \mathrm{mg} / \mathrm{dl}$ was considered to indicate successful establishment of the diabetic rat model. After confirmation of diabetes, the model rats, including $\mathrm{NC}$ group rats, received a high-fat, high-sugar diet for 7 weeks to promote the development of DGP. In order to reduce the variation between each rat group when grouping, 36 of the 48 DGP model rats were randomly assigned to the following three groups ( $\mathrm{n}=12$ /group) after DGP model establishment: i) STZ-induced group, received no further treatment; ii) low-dosage group, received $25 \mathrm{mg} / \mathrm{kg}$ atractylenolide-1 (intragastric; daily for 6 weeks; Selleck Chemicals); and iii) high-dosage group, received $75 \mathrm{mg} / \mathrm{kg}$ atractylenolide-1 (intragastric; daily for 6 weeks). The doses of atractylenolide-1 used in the present study were safe and well tolerated in Sprague-Dawley rats as determined by the Maximum Tolerated Dose study on the basis of a preliminary experiment (data not shown). The NC rats were assigned to the vehicle control group, which were intraperitoneally injected with $30 \%$ Solutol ${ }^{\circledR}$ HS15 + 0.5\% methylcellulose (daily for 6 weeks; Sigma-Aldrich; Merck KGaA). After 6 weeks of treatment, the fasting blood glucose levels was detected by OneTouch ${ }^{\circledR}$ glucometer (LifeScan IP Holdings, LLC) and glycated hemoglobin were assessed using a rat HbAlc ELISA kit (cat. no. JL12389; Shanghai Jianglai Biological Technology Co., Ltd.), and then the rats were sacrificed with an overdose of pentobarbital sodium $(150 \mathrm{mg} / \mathrm{kg}$; Sigma-Aldrich; Merck KGaA) via the tail vein. Throughout the sampling period, the rats were anesthetized via the intraperitoneal injection of $10 \%$ chloral hydrate injection $(0.3 \mathrm{~g} / \mathrm{kg})$, and no abnormal behavior or peritonitis was observed.

Gastric emptying analysis. At $30 \mathrm{~min}$ after the last dose of atractylenolide-1, the rats received $2 \mathrm{ml}$ phenol red (5\%) as standard phenol red volume by gavage. After a further $30 \mathrm{~min}$, the rats were euthanized. The entire stomach was placed in a culture dish and the gastric tissue was thoroughly washed with distilled water. Subsequently, $1 \mathrm{~mol} / \mathrm{l} \mathrm{NaOH}$ was added and evenly distributed. After standing for $1 \mathrm{~h}$, the tissues were treated with $20 \%$ trichloroacetic acid for $30 \mathrm{~min}$ to remove the protein, and then centrifuged at $5,000 \times \mathrm{g}$ at $4^{\circ} \mathrm{C}$ for $10 \mathrm{~min}$, the phenol red residue was extracted into the supernatant. The supernatant was harvested and the absorbance value was measured at a wavelength of $560 \mathrm{~nm}$ using a spectrophotometer. The gastric emptying rate was calculated as follows: Gastric emptying rate $(\%)=(1-$ measured phenol red residue/standard phenol red volume) $\mathrm{x} 100$.

Gastric peristalsis analysis. At 30 min after the last dose of atractylenolide-1, the rats were intraperitoneally anesthetized with $10 \%$ chloral hydrate. After disinfection, the abdominal wall was cut to fully expose the gastric tissue. The pylorus muscle was removed with a frog-shaped clip, and a gastric motility curve was constructed using a muscle tension transducer. A total of $10 \mathrm{~min}$ was recorded to calculate the gastric peristalsis frequency, and three representative gastric motility contraction curves were selected to calculate the average gastric peristalsis amplitude.

Gastric blood flow analysis. At 30 min after the last dose of atracytelonolide-1, the rats were anesthetized with $10 \%$ chloral hydrate. After disinfection, the gastric tissue was fully exposed and the probe of a laser-Doppler blood flow meter (ALF21 ${ }^{\mathrm{TM}}$; 
Advance Co., Ltd.) was lightly placed on the surface of the stomach. Gastric blood flow was recorded for $30 \mathrm{sec}$ after the measured value on the display had stabilized. The average gastric blood flow rate between 10 and $25 \mathrm{sec}$ was recorded as the gastric blood flow value for each rat.

ICC isolation and in vitro culture. At $30 \mathrm{~min}$ after the last dose of atracytelonolide-1, the rats were anesthetized with $10 \%$ chloral hydrate. Subsequently, the rat abdominal cavity was opened under aseptic conditions, and the stomach tissue was removed and rinsed with PBS. The tissues were then cut into pieces and $0.25 \%$ trypsin was added for digestion at $37^{\circ} \mathrm{C}$. The digested tissues were clarified using a mesh filter and centrifuged at $21,000 \mathrm{x}$ g at $20^{\circ} \mathrm{C}$ for $5 \mathrm{~min}$. After the supernatants were discarded, the cells were washed with PBS and then centrifuged at $21,000 \times \mathrm{g}, 20^{\circ} \mathrm{C}$ for $5 \mathrm{~min}$ again. The resulting ICCs were cultured at $37^{\circ} \mathrm{C}$ with $5 \% \mathrm{CO}_{2}$ in L-DMEM (cat. no. 11885092; Gibco; Thermo Fisher Scientific, Inc.) containing 10\% FBS (cat. no. 26140079; Gibco; Thermo Fisher Scientific, Inc.).

Cell proliferation assays. Cell proliferation was detected using Cell Counting Kit-8 (CCK-8; cat. no. ab228554; Abcam), according to the manufacturer's protocol. ICCs $(4,000$ cells $/ 100 \mu \mathrm{l})$ were inoculated into a 96 -well plate. After $0,24,48,72$ and $96 \mathrm{~h}$ of culturing at $37^{\circ} \mathrm{C}$, the cells in each well were incubated with $10 \mu \mathrm{l}$ CCK- 8 solution for $1 \mathrm{~h}$. Subsequently, the absorbance of each well was determined at $450 \mathrm{~nm}$ using Multiskan ${ }^{\mathrm{TM}} \mathrm{FC}$ microplate reader (cat. no. 51119180; Thermo Fisher Scientific, Inc.). The experiments were performed in triplicate.

Western blotting. The gastric tissue samples from the in vivo experiments were lysed in RIPA Lysis and Extraction Buffer (cat. no. 89901; Thermo Fisher Scientific, Inc.). The obtained proteins were quantified using BCA Protein Assay kit (cat. no. ab102536; Abcam). Then, $50 \mu \mathrm{g}$ proteins were separated via SDS-PAGE on $10 \%$ gels for $90 \mathrm{~min}$, and subsequently transferred onto PVDF membranes (EMD Millipore). These membranes were incubated with $5 \%$ non-fat milk diluted with Pierce $^{\mathrm{TM}}$ PBS Tween ${ }^{\mathrm{TM}} 20$ Buffer (cat. no. 28352; Pierce; Thermo Fisher Scientific, Inc.) for $1 \mathrm{~h}$ at room temperature. The membranes were incubated overnight at $4^{\circ} \mathrm{C}$ with the following specific primary antibodies (all purchased from Abcam): Anti-c-kit (1:,000; cat. no. ab32363), anti-SCF (1:5,000; cat. no. ab52603), anti-P53 (1:1,000; cat. no. ab131442), anti-Bcl-2 (1:1,000; cat. no. ab32124), anti-cleaved-caspase 3 (1:500; cat. no. ab32042), anti-heme oxygenase 1 (1:1,000; HO-1; cat. no. ab13243), anti- $\beta$-Catenin (1:5,000; cat. no. ab32572), anti-Survivin (1:5,000; cat. no. ab76424), anti-GAPDH $(1: 2,500$; cat. no. ab9485) and anti- $\alpha$-tubulin (1:5,000; cat. no. ab7291). Subsequently, the membranes were incubated with HRP-conjugated goat anti-mouse (1:1,000; cat. no. 1706516; Bio-Rad Laboratories, Inc.) or goat anti-rabbit (1:1,000; cat. no. 1706515; Bio-Rad Laboratories, Inc.) secondary antibodies for $1 \mathrm{~h}$ at room temperature. After washing three times with TBS containing 5\% Tween-20 (Sigma-Aldrich; Merck KGaA), the blots were visualized using Novex ${ }^{\mathrm{TM}}$ ECL Chemiluminescent Substrate Reagent Kit (cat. no. WP20005; Invitrogen; Thermo Fisher Scientific, Inc.). Image Lab 3.0 software (Bio-Rad
Laboratories, Inc.) was used to semi-quantify protein expression of each band. GAPDH and $\alpha$-tubulin were used as the loading controls.

ELISA assay. The ELISA kits for SCF (cat. no. ab100740; Abcam), HbA1c (cat. no. JL12389; Shanghai Jianglai Biological Technology Co., Ltd.) and SOD (cat. no. JL22893; Shanghai Jianglai Biological Technology Co., Ltd.) were incubated at room temperature for $30 \mathrm{~min}$ prior to use and performed according to the manufacturer's protocol. Then, $50 \mu \mathrm{l}$ standard and diluted serum from different groups of rats were added into the wells of plates. Subsequently, $100 \mu 1$ enzyme-linked reagents from ELISA kits were added into each well and incubated at $37^{\circ} \mathrm{C}$ for $1 \mathrm{~h}$. The mixture supernatant in each well was discarded and the developing agents were added at room temperature for $20 \mathrm{~min}$ in the dark. Finally, the absorbance of each well was determined at $450 \mathrm{~nm}$ using Multiskan $^{\mathrm{TM}}$ FC microplate reader (cat. no. 51119180; Thermo Fisher Scientific, Inc.)

Membrane protein isolation and evaluation. The membrane proteins from snap-frozen stomach tissue samples were isolated using the Minute ${ }^{\mathrm{TM}}$ Plasma Membrane Protein Isolation and Cell Fractionation Kit (cat. no. SM-005; Invent Biotechnologies, Inc.) according to the manufacturer's protocol. Samples were collected and resuspended with buffer $\mathrm{A}$ in the Minute ${ }^{\mathrm{TM}}$ Plasma Membrane Protein Isolation and Cell Fractionation Kit supplemented with protease inhibitor cocktail (cat. no. ab65621; Abcam). Total membrane proteins were isolated from buffer A supplemented with protease inhibitor cocktail and evaluated by western blotting, according to the aforementioned method, using $\beta$-catenin as the loading control.

Detection of apoptosis viaflow cytometry. Flow cytometry was performed using the Annexin V-FITC/PI Apoptosis Detection Kit (cat. no. A211-01; Vazyme Biotech Co., Ltd.) to assess apoptosis in rat gastric tissues. Briefly, the gastric tissues were trypsinized, rinsed twice with PBS and resuspended in $100 \mu 1$ 1X Binding buffer. Subsequently, the cells were stained with $5 \mu \mathrm{l}$ Annexin V-FITC and $5 \mu \mathrm{l}$ PI Staining Solution in the dark for $10 \mathrm{~min}$ at room temperature $\left(20-25^{\circ} \mathrm{C}\right)$ and then $400 \mu \mathrm{l}$ $1 \mathrm{X}$ Binding buffer was added. After Annexin V/PI staining, the samples were immediately analyzed via flow cytometry (FACSCalibur; BD Biosciences). Gastric cells were identified as viable, necrotic and apoptotic cells using CellQuest software (version 5.0; BD Biosciences). The Annexin $\mathrm{V}^{+} / \mathrm{PI}^{+}$quadrant in the flow cytometry plots represents the late apoptotic cells and Annexin $\mathrm{V}^{+} / \mathrm{PI}^{-}$quadrant represents the early apoptotic cells.

Reverse transcription-quantitative PCR (RT-qPCR). Total RNA was extracted from gastric tissues using TRIzol ${ }^{\circledR}$ reagent (Invitrogen; Thermo Fisher Scientific, Inc.) and reverse transcribed into cDNA using the PrimeScript ${ }^{\mathrm{TM}}$ RT Master Mix (Takara Biotechnology Co., Ltd.) according to the manufacturer's instructions. Subsequently, qPCR was performed using SYBR-Green PCR Master Mix (cat.no. QPK-201T; Toyobo Life Science) and the ABI Prism 7900 sequence detection system (Applied Biosystems; Thermo Fisher Scientific, Inc.) under the following conditions, according to the manufacturer's protocol: 
Initial denaturation at $95^{\circ} \mathrm{C}$ for $2 \mathrm{~min}$; followed by 40 cycles at $95^{\circ} \mathrm{C}$ for $10 \mathrm{sec}, 60^{\circ} \mathrm{C}$ for $30 \mathrm{sec}$ and $72^{\circ} \mathrm{C}$ for $30 \mathrm{sec}$; and then melting curve analysis. mRNA expression levels were quantified using the $2^{-\Delta \Delta \mathrm{Cq}}$ method (29) and normalized to the internal reference gene $\beta$-actin. The following primers were used for qPCR: HO-1 forward, 5'-CGGGCCAGCAACAAAGTG-3' and reverse, 5'-AGTGTAAGGACCCATCGGAGAA-3'; and $\beta$-actin forward, 5'-TCCTCCCTGGAGAAGAGCTA-3' and reverse, 5'-TCAGGAGGAGCAATGTTG-3'.

Immunohistochemistry (IHC). To evaluate the number and distribution of ICCs, gastric ICCs were rapidly sampled from the rats, fixed in $4 \%$ formalin at room temperature for $30 \mathrm{~min}$, and then embedded in paraffin. The paraffin blocks were cut into 4- $\mu \mathrm{m}$ sections, deparaffinized in xylene and rehydrated in a descending alcohol series (100, 95 and 80\%). Endogenous peroxidase activity was blocked by incubating the tissue sections in $30 \% \mathrm{H}_{2} \mathrm{O}_{2}$ for $30 \mathrm{~min}$, after which antigen retrieval was performed at $37^{\circ} \mathrm{C}$ for $10 \mathrm{~min}$. The sections were then incubated overnight at $4^{\circ} \mathrm{C}$ with the anti-c-Kit primary antibody (1:1,000; cat. no. ab32363; Abcam). Then, the sections were incubated with a HRP-labeled goat anti-rabbit secondary antibody (1:1,000; cat. no. 1706515; Bio-Rad Laboratories, Inc.) at $37^{\circ} \mathrm{C}$ for $2 \mathrm{~h}$. The sections were then stained with diaminobenzidine at room temperature for $20 \mathrm{~min}$ and counterstained with hematoxylin at room temperature for $5 \mathrm{~min}$. Finally, images were captured using a light microscope (BX53; Olympus Corporation).

Malondialdehyde (MDA) assay. The detection of MDA levels in gastric tissue from different groups of rats was performed using the Lipid Peroxidation (MDA) Assay Kit (cat. no. ab118970; Abcam) according to the manufacturer's instructions. The gastric tissues were digested into single cells and collected with $600 \mu 1$ MDA lysis buffer supplemented with butylated hydroxytoluene using a cell scraper. Cell lysates were centrifuged at $13,000 \mathrm{x} \mathrm{g}, 4^{\circ} \mathrm{C}$ for $10 \mathrm{~min}$. The supernatants were collected and divided into three replicates of $180 \mu \mathrm{l}$, and the remaining $50 \mu \mathrm{l}$ for Qubit ${ }^{\mathrm{TM}}$ dsDNA HS Assay Kit (Thermo Fisher Scientific, Inc.) protein concentration measurement. Then, $600 \mu \mathrm{l}$ of $10 \mathrm{mg} / \mathrm{ml}$ TBA solution from the Lipid Peroxidation (MDA) Assay Kit was added to each replicate in a 96-well plate, and incubated at $95^{\circ} \mathrm{C}$ for $1 \mathrm{~h}$, followed by immediate detection using a Multiskan ${ }^{\mathrm{TM}}$ FC microplate reader (cat. no. 51119180; Thermo Fisher Scientific, Inc.) at $\mathrm{Ex} / \mathrm{Em}=532 / 553 \mathrm{~nm}$ for the fluorometric assay. MDA protein from each sample was normalized to the MDA protein concentration.

Statistical analysis. Data are presented as the mean \pm SEM $(n=3 / 6 / 12)$. In vitro experiments were repeated three times. Comparisons among multiple groups were analyzed using one-way ANOVA or two-way mixed ANOVA followed by Tukey's post hoc test. Statistical analyses were performed using SPSS 17.0 software (SPSS, Inc.). $\mathrm{P}<0.05$ was considered to indicate a statistically significant difference.

\section{Results}

Effects of atractylenolide-1 on glycemia, glycated hemoglobin levels and body weight in DGP rats. As shown in Table I,
Table I. Effects of atractylenolide-1 on fasting glucose and glycosylated hemoglobin levels in diabetic gastroparesis model rats.

\begin{tabular}{lcc}
\hline Group & $\begin{array}{c}\text { Fasting } \\
\text { glucose, } \\
\mathrm{mg} / \mathrm{dl}\end{array}$ & $\begin{array}{c}\text { Glycated } \\
\text { hemoglobin, } \\
\%\end{array}$ \\
\hline Vehicle control & $92.5 \pm 12.4$ & $4.2 \pm 0.6$ \\
STZ-induced & $505.7 \pm 34.5^{\mathrm{a}}$ & $16.8 \pm 1.3^{\mathrm{a}}$ \\
Atractylenolide-1 $25 \mathrm{mg} / \mathrm{kg}$ & $192.4 \pm 44.7^{\mathrm{b}}$ & $8.3 \pm 0.9^{\mathrm{b}}$ \\
Atractylenolide-1 $75 \mathrm{mg} / \mathrm{kg}$ & $175.9 \pm 31.4^{\mathrm{b}}$ & $8.1 \pm 1.5^{\mathrm{b}}$ \\
\hline
\end{tabular}

Data are presented as the mean \pm SEM $(n=12)$. ${ }^{a} \mathrm{P}<0.001$ vs. vehicle control group; ${ }^{\mathrm{b}} \mathrm{P}<0.01 \mathrm{vs}$. STZ-induced group. STZ, streptozotocin.

compared with the vehicle control group, fasting blood glucose and glycated hemoglobin levels were significantly increased in rats from the STZ-induced group, which confirmed diabetic status. Compared with the STZ-induced group, rats receiving different doses of atractylenolide-1 displayed significantly decreased fasting blood glucose and glycated hemoglobin levels. However, there were no significant differences between the high- and low-dose atractylenolide-1 groups. As predicted, animals in the vehicle control group displayed fasting blood glucose and glycated hemoglobin levels within the normal range (normal range of fasting blood glucose, $50.40-136.08 \mathrm{mg} / \mathrm{dl}$; normal range of glycated hemoglobin, 3.6-6.0\%) (30). Moreover, STZ-induced rats displayed significantly decreased body weights compared with the vehicle control rats at each time point (Table II). However, compared with the STZ-induced group, the body weights of the rats in the atractylenolide- 1 treatment groups were increased after 6 weeks of treatment, but remained below those of the vehicle control group.

Effects of atractylenolide-1 on gastric function in DGP model rats. Previous studies have reported that gastric emptying, motility, peristalsis and blood flow are significantly impaired in rats with gastroparesis $(21,31)$. In the present study, gastric function was significantly weakened in STZ-induced rats compared with that in the vehicle control group. However, gastric function was significantly restored in STZ-induced rats following treatment with atractylenolide-1 (Fig. 1). Compared with the STZ-induced group, the rate of gastric emptying was significantly restored in both the low- and high-dose atractylenolide-1 groups (Fig. 1A). Furthermore, the frequency and gastric blood flow were significantly enhanced in DGP model rats treated with atractylenolide-1, and the amplitude of gastric peristalsis was also significantly increased in high-dose atractylenolide-1groups (Fig. 1B-D). Collectively, these data indicated that atractylenolide-1 displayed a positive effect on the recovery of gastric function in DGP model rats.

Effects of atractylenolide-1 on the expression of gastrointestinal peristalsis-associated proteins in vivo. The successful establishment of an STZ-induced DGP rat model was confirmed by a series of experiments investigating the effects 
A
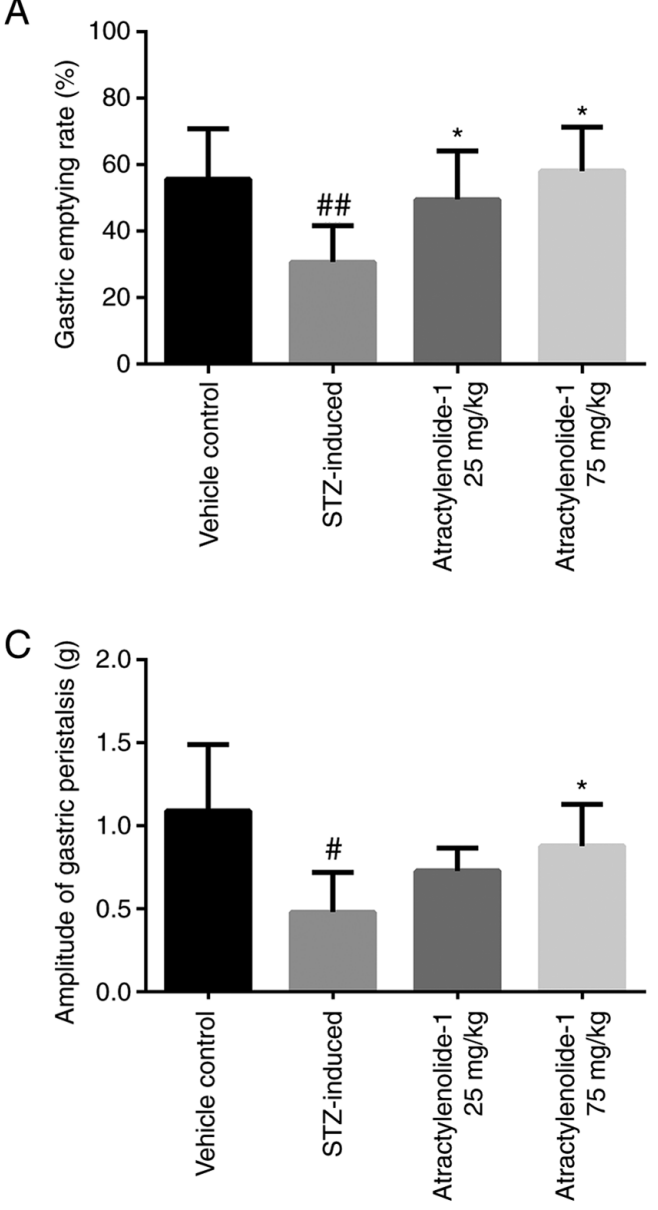

B

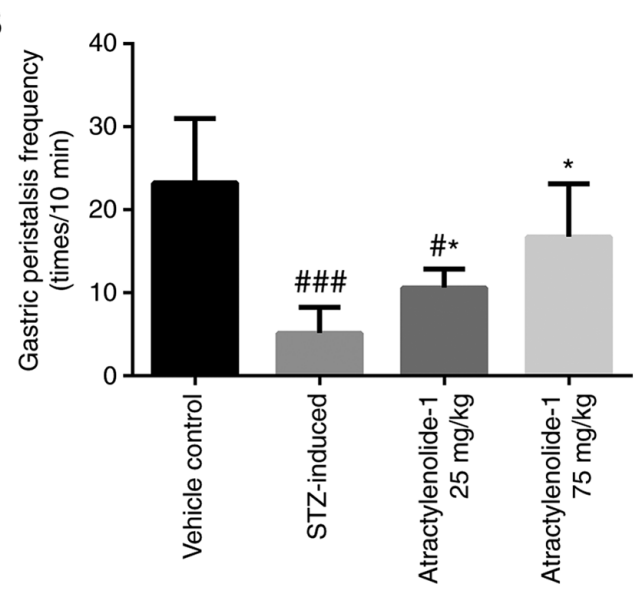

D

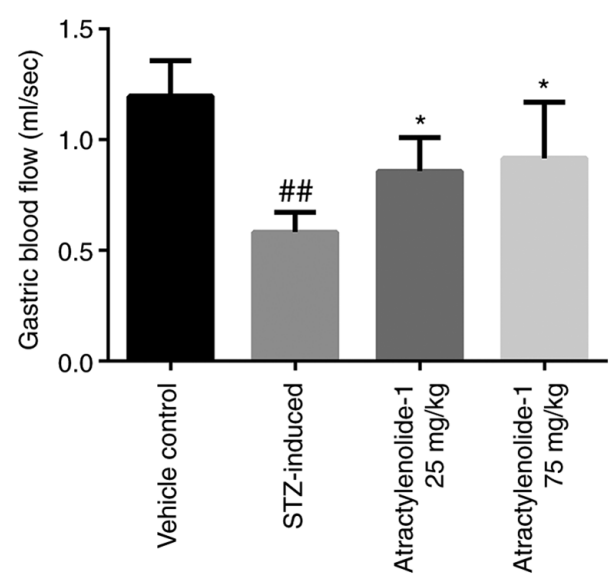

Figure 1. Effects of atractylenolide-1 on gastric function in diabetic gastroparesis model rats. (A) Gastric emptying. (B) Frequency and (C) amplitude of gastric peristalsis. (D) Gastric blood flow. Data are presented as the mean \pm SEM $(n=6)$. ${ }^{\#} \mathrm{P}<0.05,{ }^{\# \#} \mathrm{P}<0.01$ and ${ }^{\# \# \#} \mathrm{P}<0.001$ vs. vehicle control group; ${ }^{*} \mathrm{P}<0.05$ vs. STZ-induced group. STZ, streptozotocin.

of atractylenolide-1 on DPG. By performing IHC analysis, the expression of c-kit was detected in gastric tissues from different groups. Compared with the control group, the expression level of c-kit was largely suppressed in the STZ-induced model group and was then elevated by atractylenolide- 1 treatment (Fig. 2A). Compared with ICCs in the vehicle control group, c-kit protein expression was markedly suppressed in the STZ-induced group, but notably restored in the atractylenolide-1 treatment groups (Fig. 2B). Compared with the STZ-induced group, the concentration of SCF protein in rat serum and the expression levels of membranous SCF in the gastric tissue samples were increased following treatment with atractylenolide-1 (Fig. 2C and D). The results suggested that atractylenolide-1 activated the expression of proteins associated with gastrointestinal peristalsis signaling pathways and improved gastrointestinal function.

Atractylenolide-1 promotes cellular proliferation in DGP. To further investigate the effects of atractylenolide-1 on gastric cell proliferation, cultured ICCs were isolated from gastric tissues in vitro. As shown in Fig. 2E, the cellular proliferation rate of the STZ-induced group was markedly lower compared with the vehicle control group. However, proliferation in the atractylenolide- 1 treatment groups was markedly increased compared with the STZ-induced group. These results further suggested that atractylenolide-1 treatment promoted gastric ICC proliferation in the DGP rat model.

Atractylenolide-1 suppresses apoptosis in the DGP rat model. A previous study identified that ICC apoptosis in gastric tissues is significantly increased during diabetic gastroparesis (unpublished data). Therefore, the present study aimed to determine whether atractylenolide-1 could regulate DGP-associated apoptosis. ICCs were separated from gastric tissues and apoptosis was evaluated via flow cytometry (Fig. 3A and B). Compared with the vehicle control group (late apoptosis, $8.3 \%$; early apoptosis, $11.2 \%$ ), the apoptotic rate was significantly increased in the STZ-induced group (late apoptosis, 22.3\%; early apoptosis, 19.8\%). However, compared with the STZ-induced group, the apoptotic rate was significantly decreased following high-dose atractylenolide- 1 treatment. To investigate the molecular mechanisms underlying atractylenolide-1-mediated regulation of apoptosis, the expression of apoptosis-related proteins in ICCs, including Survivin, P53, Bcl-2 and cleaved-caspase-3, was detected by performing western blotting. Compared with the STZ-induced group, atractylenolide-1 markedly decreased the protein expression levels of P53 and cleaved-caspase-3, but notably increased the expression levels of Survivin and Bcl-2 (Fig. 3C). These results further demonstrated that atractylenolide-1 reversed STZ-induced ICC apoptosis. 
A

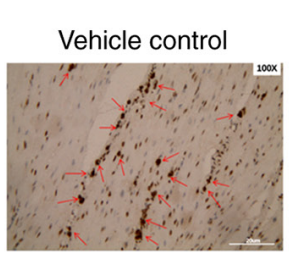

C

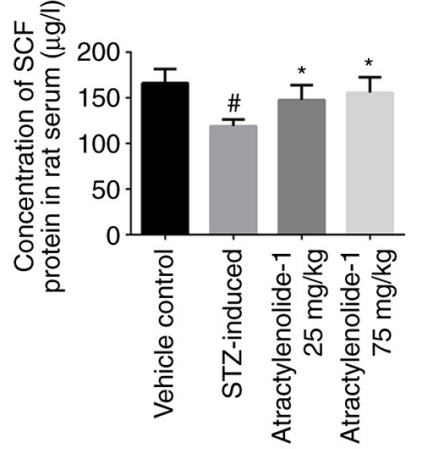

STZ-induced

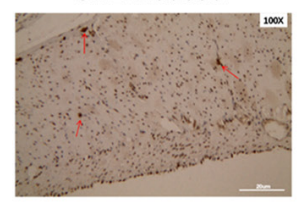

D

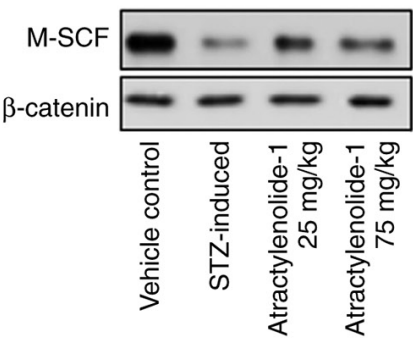

Atractylenolide-1 $75 \mathrm{mg} / \mathrm{kg}$

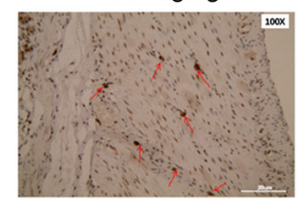

$\mathrm{E}$

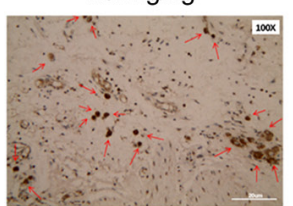

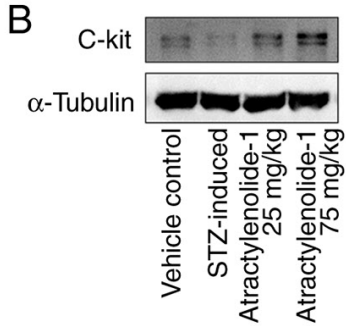

$\rightarrow$ Vehicle control

- STZ-induced

ـ Atractylenolide-1 25 mg/kg

$\rightarrow$ Atractylenolide-1 75 mg/kg

Figure 2. Effects of atractylenolide-1 on the SCF/c-kit signaling pathway in diabetic gastroparesis model rats. (A) Expression of c-kit in formalin-fixed, paraffin-embedded gastric tissues was detected by performing immunohistochemistry (red arrows indicate the c-kit-positive cells in gastric tissue). Magnification, x100. (B) Protein expression levels of c-kit in gastric ICCs were determined by western blotting using $\alpha$-tubulin as the loading control. (C) SCF protein concentrations in rat serum were determined by performing ELISAs. (D) M-SCF protein expression levels in rat gastric tissue samples were determined by western blotting using $\beta$-catenin as the loading control. (E) ICC proliferation was determined by performing the Cell Counting Kit- 8 assay. Data are presented as the mean $\pm \mathrm{SEM}(\mathrm{n}=12)$. ${ }^{\text {" }} \mathrm{P}<0.05$ vs. vehicle control group; ${ }^{\mathrm{P}} \mathrm{P}<0.05$ vs. STZ-induced group. SCF, stem cell factor; c-kit, KIT proto-oncogene, receptor tyrosine kinase; ICCs, interstitial cells of Cajal; M-SCF, membranous SCF; STZ, streptozotocin.
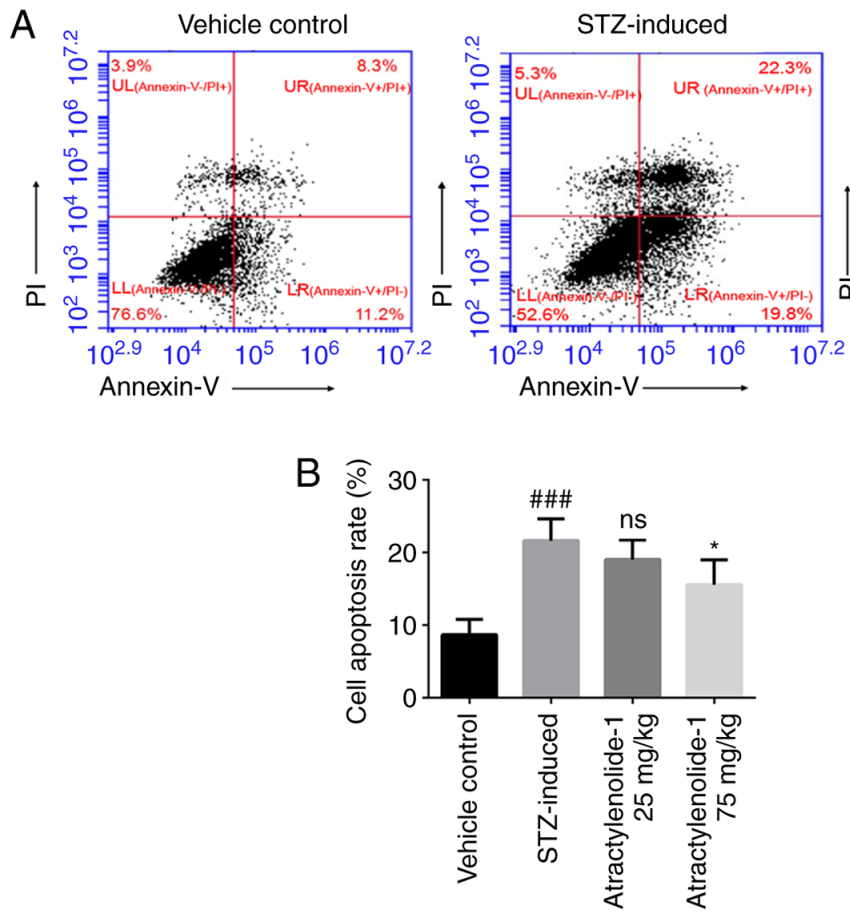

Atractylenolide-1 $25 \mathrm{mg} / \mathrm{kg}$
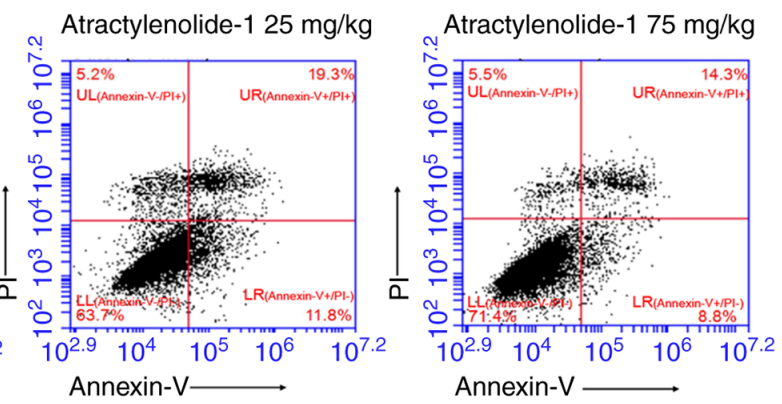

C

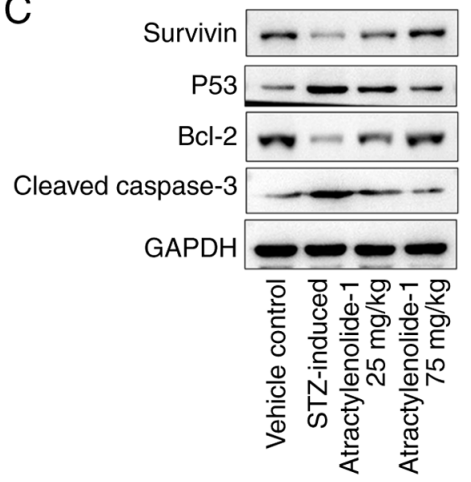

Figure 3. Atractylenolide-1 treatment regulates apoptosis in diabetic gastroparesis model rats. (A) Flow cytometry was performed to determine the apoptotic rate of ICCs. After staining with Annexin V-FITC and PI, apoptosis was evaluated. The LL, UL, LR and UR quadrants of each panel show viable, necrotic (non-viable), early apoptotic and late apoptotic cells, respectively. (B) Quantification of apoptosis. (C) Apoptosis-associated protein expression levels in ICCs were determined by western blotting using $\alpha$-tubulin as the loading control. Data are presented as the mean \pm SEM $(n=6)$. ${ }^{\# \# ~} \mathrm{P}<0.001$ vs. vehicle control group; "P<0.05, vs. STZ-induced group. ICCs, interstitial cells of Cajal; STZ, streptozotocin; LL, lower left; UL, upper left; LR, lower right; UR, upper right; ns, not significant.

Regulatory effects of atractylenolide-1 on oxidative stress and $H O-1$ protein expression in DGP model rats. Superoxide dismutase (SOD) is an important antioxidant in the gastric mucosa, and its depletion is associated with the production of reactive oxygen species under oxidative stress conditions (32). In the STZ-induced group, the SOD serum content was significantly 
Table II. Effects of atractylenolide-1 on the body weight in diabetic gastroparesis model rats.

\begin{tabular}{lcccc}
\hline & \multicolumn{3}{c}{ Body weight, g } \\
\cline { 2 - 4 } Group & Before treatment & $\begin{array}{c}2 \text { weeks } \\
\text { post-treatment }\end{array}$ & $\begin{array}{c}4 \text { weeks } \\
\text { post-treatment }\end{array}$ & $\begin{array}{c}6 \text { weeks } \\
\text { post-treatment }\end{array}$ \\
\hline Vehicle control & $353.6 \pm 40.0$ & $417.7 \pm 36.9$ & $456.2 \pm 28.7$ & $481.6 \pm 25.8$ \\
STZ-induced & $179.4 \pm 35.0^{\mathrm{a}}$ & $181.8 \pm 78.1^{\mathrm{b}}$ & $210.3 \pm 85.1^{\mathrm{a}}$ & $269.4 \pm 57.6^{\mathrm{a}}$ \\
Atractylenolide-1 $25 \mathrm{mg} / \mathrm{kg}$ & $187.7 \pm 56.6$ & $218.3 \pm 59.2$ & $246.5 \pm 61.8^{\mathrm{c}}$ & $290.3^{\mathrm{b}} \pm 40.8^{\mathrm{c}}$ \\
Atractylenolide-1 $75 \mathrm{mg} / \mathrm{kg}$ & $179.3 \pm 51.0$ & $244.2 \pm 55.3^{\mathrm{c}}$ & $277.4 \pm 62.7^{\mathrm{c}}$ & $285.7 \pm 61.2^{\mathrm{c}}$ \\
\hline
\end{tabular}

Data are presented as the mean \pm SEM $(n=12)$. ${ }^{a} \mathrm{P}<0.01$ and ${ }^{\mathrm{b}} \mathrm{P}<0.001$ vs. vehicle control group; ${ }^{\mathrm{c}} \mathrm{P}<0.05$ vs. STZ-induced group. STZ, streptozotocin.

A

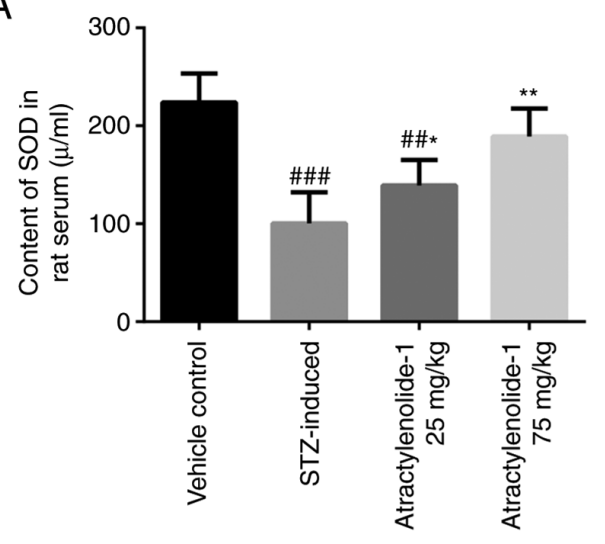

B

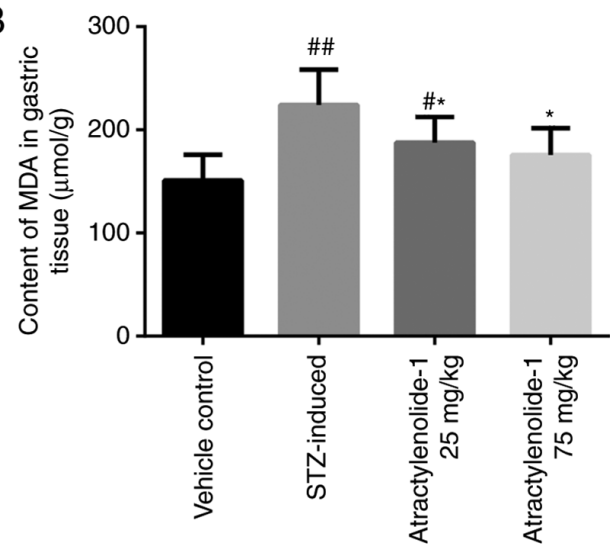

C

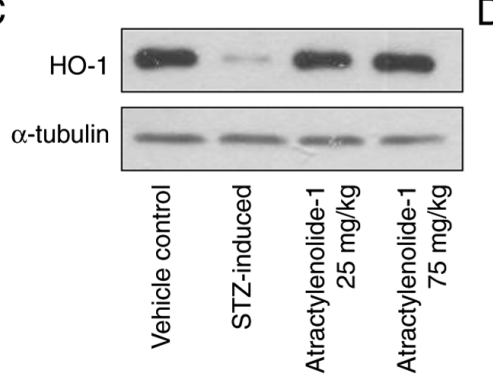

D

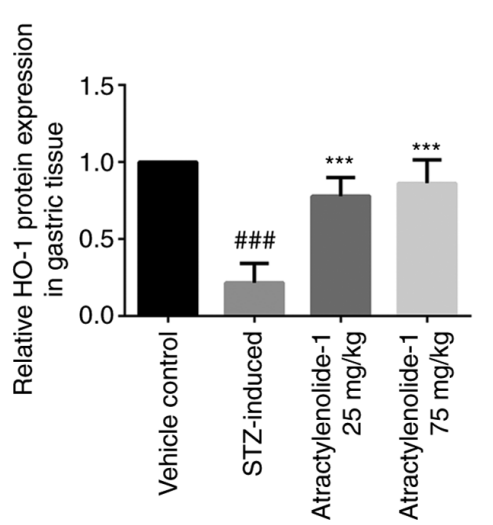

E

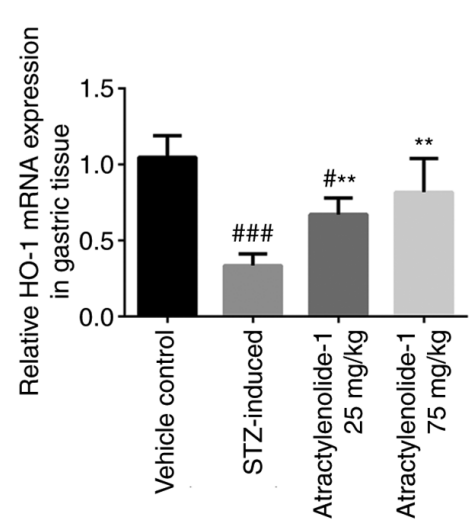

Figure 4. Regulatory effects of atractylenolide-1 on oxidative stress in diabetic gastroparesis model rats. (A) Concentration of SOD in rat serum measured using a SOD ELISA kit. (B) Concentration of MDA in rat gastric tissues measured using an MDA assay kit. HO-1 protein expression levels in gastric tissues were $(\mathrm{C})$ determined by western blotting using $\alpha$-tubulin as a loading control and (D) semi-quantified (n=3/group). (E) HO-1 mRNA expression levels in gastric tissues were detected by reverse transcription-quantitative PCR. Data are presented as the mean \pm SEM $(\mathrm{n}=12)$. ${ }^{\# \mathrm{P}}<0.05$, ${ }^{\# \prime} \mathrm{P}<0.01$ and

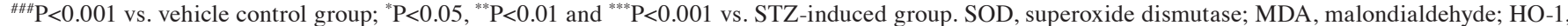
heme oxygenase; STZ, streptozotocin.

decreased compared with that in the vehicle control group. By contrast, atractylenolide-1 treatment significantly recovered the content of SOD in DGP model rats (Fig. 4A). Consistent with the changes in SOD content, the content of malondialdehyde (MDA), which is directly associated with oxidative stress (33), was also significantly altered. Atractylenolide-1 treatment significantly reduced the content of MDA in gastric tissues compared with that in the STZ-induced group (Fig. 4B).
The expression of the HO-1 protein in rat serum alleviates the effects of high oxidative stress, increases the number of ICCs and improves the network structure of the gastric tissue, thus reversing the effects of DGP on gastric emptying (19). The results of the present study further demonstrated that atractylenolide-1 significantly restored the expression of HO-1 in STZ-induced DGP model rats, thus reversing STZ-induced oxidative stress (Fig. 4C-E). Collectively, these 
results suggested that atractylenolide-1 alleviated oxidative stress reactions and restored gastrointestinal function in DGP model rats.

\section{Discussion}

As a frequent chronic complication of diabetes, the most common symptoms of DGP are gastric motility disorder, marked weakening of gastric motility, delayed gastric emptying and gastric rhythm disturbances. DGP causes upper gastrointestinal symptoms, such as early satiety, nausea and vomiting, which can be severe and difficult to treat. Effective medications can increase the rates of diabetic morbidity and mortality through severe nutritional loss and impaired glycemic control $(6,7)$. Despite great efforts, the current treatment options for gastroparesis remain unsatisfactory (3-5). Previously, researchers have focused on the pathogenic mechanisms underlying DGP, and previous studies have reported that DGP may be associated with hyperglycemia and ICC lesions $(33,34)$. As an important means of maintaining normal gastric emptying, studies on ICC abnormalities are limited. In a model of type 2 diabetic $d b / d b$ mice, the myenteric interstitial cells of Cajal and intramuscular interstitial cells of Cajal decreased with an increase in gastric motility disorder in the gastric sinus tissue (34). Another retrospective study demonstrated that patients with DGP experienced disruptions of the ICC network in the gastric sinus tissue (13). Furthermore, the number of ICCs were found to be significantly reduced in the gastric sinus tissue of patients with DGP, gastric tachycardia or slow wave rhythm disorder, a symptom associated with ICC lesions $(17,18)$. The aforementioned studies indicated that ICCs are a key factor in the development of DGP.

c-kit is a transmembrane tyrosine kinase receptor expressed by ICCs that regulates gastric contractions (15). In previous studies, SCF expression was found to increase the number of ICCs, enhance gastrointestinal motility and repair ICC structural lesions $(20,21)$. Previous reports have indicated that SCF mRNA expression was significantly decreased in the gastric tissues of STZ-induced DGP model rats, with a decrease in c-kit protein expression, the development of ICC ultrastructural lesions and delayed gastric emptying $(20,21)$. Treatment with exogenous SCF improved or reversed ICC-associated pathological alterations and gastrointestinal motility disorders in diabetic model mice (35). In the present study, compared with the vehicle control group, the expression of c-kit in ICCs was notably suppressed in the STZ-induced group, which was subsequently markedly elevated by atractylenolide- 1 . The concentration of serum SCF was also significantly increased and ICC proliferation was markedly enhanced in the atractylenolide-1 treatment groups compared with in the STZ-induced group. These results suggested that atractylenolide-1 regulated the number and stability of ICCs. Furthermore, flow cytometry and western blotting revealed that, compared with the vehicle control group, ICC apoptosis was significantly increased in the STZ-induced group, but decreased following atractylenolide-1 administration, suggesting that atractylenolide-1 promoted ICC proliferation, inhibited apoptosis and enhanced gastric motility.
The primary clinical treatment of DGP aims to alleviate symptoms by improving gastric emptying, long-term regulation of blood sugar and nutritional support. However, optimal treatment options are still lacking, and relapse after a long period of medication is common $(4,5,9)$. Due to the side effects of current DGP treatments, the discovery of effective treatment methods is urgently required. As a representative Traditional Chinese Medicine (TCM), A. macrocephala has been used in clinical treatment for a number of years and displays considerable therapeutic effects in the repair of gastrointestinal function (22-25). A retrospective clinical study demonstrated its ability to improve the clinical symptoms of patients with DGP (36). In the present study, the therapeutic potential of atractylenolide-1, a major bioactive compound of A. macrocephala, was evaluated following the impairment of gastric motility in STZ-induced DGP model rats. The results indicated that atractylenolide-1 significantly improved the rate of gastric emptying, the frequency and amplitude of gastric peristalsis, and gastric blood flow in DGP model rats. Atractylenolide-1 also significantly reduced the levels of blood glucose and glycated hemoglobin, and significantly increased body weight in DGP model rats. These data suggested that atractylenolide-1 positively influenced the recovery of gastric function in DGP model rats.

Oxidative stress serves an important role in the etiology of disease and is considered to be a major factor in the development of diabetic complications and tissue damage $(19,37)$. Oxidative stress is responsible for various diabetic complications of the organs, causing gastric mucosal damage and gastric dyskinesia, including DGP $(20,31)$. Gastroparesis is speculated to be caused by impairment of ICC network formation as a result of oxidative stress (38). Previous studies have reported that gastric motility was significantly weaker in DGP model rats compared with in control rats, and that the level of MDA in the gastric tissue was increased, but the level of serum SOD was decreased, indicating that oxidative stress was significantly enhanced in the gastric tissues of DGP model rats. However, following antioxidant treatment, the levels of SCF/c-kit were increased and the number of apoptotic ICCs was decreased, suggesting improved gastric motility $(20,31)$. In the present study, atractylenolide-1 significantly enhanced the serum SOD content and decreased the MDA content in gastric tissues of DGP model rats. Atractylenolide- 1 also regulated the expression of oxidative stress-related protein HO-1 in DGP model rats, suggesting inhibition of oxidative stress responses and prevention of gastric tissue injury.

By preliminarily assessing the effects of atractylenolide-1 on DGP, the present study indicated that atractylenolide-1 accelerated gastric emptying and attenuated gastric oxidative stress by regulating ICC function in STZ-induced DGP model rats. Although atractylenolide-1 has been used in clinical practice for some time, the complexity of TCM makes it difficult to elucidate its underlying mechanisms in DGP treatment, as well as the key molecules involved, thus further investigations are required.

\section{Acknowledgements}

Not applicable. 


\section{Funding}

The present study was supported by The National Natural Science Foundation of China (grant no. 81603586) and the Youth Fund of Natural Science Foundation of Jiangsu Province (grant no. BK20151046).

\section{Availability of data and materials}

The datasets used and/or analyzed during the current study are available from the corresponding author on reasonable request.

\section{Authors' contributions}

HL and WC was responsible for the conception and writing of the manuscript. XBZ, XXZ, CG and LMG provided the study materials, designed the study and analyzed the data. HL, WC and CYP performed the experiments and collected the data. YZT and ML provided administrative support, analyzed, interpreted the data and revised the manuscript. YZT and ML confirm the authenticity of all the raw data. All authors wrote the manuscript, and read and approved the final manuscript.

\section{Ethics approval and consent to participate}

The present study was approved by the Institutional Animal Ethics Committee of the Nanjing Medical University (approval no. IACUC-1703031; Nanjing, China) and was conducted by the team at Nanjing University of Chinese Medicine.

\section{Patient consent for publication}

Not applicable.

\section{Competing interests}

The authors declare that they have no competing interests.

\section{References}

1. Jung HK: The incidence, prevalence, and survival of gastroparesis in olmsted county, Minnesota, 1996-2006 (gastroenterology 2009;136:1225-1233). J Neurogastroenterol Motil 16: 99-100, 2010.

2. Vinik AI and Ziegler D: Diabetic cardiovascular autonomic neuropathy. Circulation 115: 387-397, 2007.

3. Choung RS, Locke GR III, Schleck CD, Zinsmeister AR, Melton LJ III and Talley NJ: Risk of gastroparesis in subjects with type 1 and 2 diabetes in the general population. Am J Gastroenterol 107: $82-88,2012$

4. Camilleri M: Advances in diabetic gastroparesis. Rev Gastroenterol Disord 2: 47-56, 2002.

5. Camilleri M, Parkman HP, Shafi MA, Abell TL and Gerson L; American College of Gastroenterology: Clinical guideline: Management of gastroparesis. Am J Gastroenterol 108: 18-37, quiz 38, 2013.

6. Wang CP, Kao CH, Chen WK, Lo WY and Hsieh CL: A single-blinded, randomized pilot study evaluating effects of electroacupuncture in diabetic patients with symptoms suggestive of gastroparesis. J Altern Complement Med 14: 833-839, 2008.

7. Thazhath SS, Jones KL, Horowitz M and Rayner CK: Diabetic gastroparesis: Recent insights into pathophysiology and implications for management. Expert Rev Gastroenterol Hepatol 7: $127-139,2013$
8. Talley NJ, Young L, Bytzer P, Hammer J, Leemon M, Jones M and Horowitz M: Impact of chronic gastrointestinal symptoms in diabetes mellitus on health-related quality of life. Am J Gastroenterol 96: 71-76, 2001.

9. Abell TL, Bernstein RK, Cutts T, Farrugia G, Forster J, Hasler WL, McCallum RW, Olden KW, Parkman HP, Parrish CR, et al: Treatment of gastroparesis: A multidisciplinary clinical review. Neurogastroenterol Motil 18: 263-283, 2006.

10. Syed AA, Rattansingh A and Furtado SD: Current perspectives on the management of gastroparesis. J Postgrad Med 51: 54-60, 2005.

11. Santhanam P, Marashdeh W and Solnes L: Functional imaging of evaluation of diabetic gastroparesis. Curr Diabetes Rev 14: 222-226, 2018

12. Vinik AI, Erbas T and Casellini CM: Diabetic cardiac autonomic neuropathy, inflammation and cardiovascular disease. J Diabetes Investig 4: 4-18, 2013.

13. Moraveji S, Bashashati M, Elhanafi S, Sunny J, Sarosiek I, Davis B, Torabi A and McCallum RW: Depleted interstitial cells of Cajal and fibrosis in the pylorus: Novel features of gastroparesis. Neurogastroenterol Motil 28: 1048-1054, 2016.

14. Thuneberg L: Interstitial cells of Cajal: Intestinal pacemaker cells? Adv Anat Embryol Cell Biol 71: 1-130, 1982.

15. Rich A, Miller SM, Gibbons SJ, Malysz J, Szurszewski JH and Farrugia G: Local presentation of Steel factor increases expression of c-kit immunoreactive interstitial cells of Cajal in culture. Am J Physiol Gastrointest Liver Physiol 284: G313-G320, 2003.

16. Faussone Pellegrini MS, Cortesini C and Romagnoli P: Ultrastructure of the tunica muscularis of the cardial portion of the human esophagus and stomach, with special reference to the so-called Cajal's interstitial cells. Arch Ital Anat Embriol 82: 157-177, 1977 (In Italian).

17. Forster J, Damjanov I, Lin Z, Sarosiek I, Wetzel P and McCallum RW: Absence of the interstitial cells of Cajal in patients with gastroparesis and correlation with clinical findings. J Gastrointest Surg 9: 102-108, 2005.

18. Iwasaki H, Kajimura M, Osawa S, Kanaoka S, Furuta T, Ikuma $\mathrm{M}$ and Hishida A: A deficiency of gastric interstitial cells of Cajal accompanied by decreased expression of neuronal nitric oxide synthase and substance $\mathrm{P}$ in patients with type 2 diabetes mellitus. J Gastroenterol 41: 1076-1087, 2006.

19. Choi KM, Gibbons SJ, Nguyen TV, Stoltz GJ, Lurken MS, Ordog T, Szurszewski JH and Farrugia G: Heme oxygenase-1 protects interstitial cells of Cajal from oxidative stress and reverses diabetic gastroparesis. Gastroenterology 135: 2055-2064, 2064 e1-2, 2008.

20. Jin QH, Shen HX, Wang H, Shou QY and Liu Q: Curcumin improves expression of SCF/c-kit through attenuating oxidative stress and NF- $\mathrm{KB}$ activation in gastric tissues of diabetic gastroparesis rats. Diabetol Metab Syndr 5: 12, 2013.

21. Feng J, Gao J, Zhou S, Liu Y, Zhong Y, Shu Y, Meng MS, Yan J, Sun D, Fang Q, et al: Role of stem cell factor in the regulation of ICC proliferation and detrusor contraction in rats with an underactive bladder. Mol Med Rep 16: 1516-1522, 2017.

22. Song HP, Li RL, Zhou C, Cai X and Huang HY: Atractylodes macrocephala Koidz stimulates intestinal epithelial cell migration through a polyamine dependent mechanism. J Ethnopharmacol 159: 23-35, 2015.

23. Hossen MJ, Chou JY, Li SM, Fu XQ, Yin C, Guo H, Amin A, Chou GX and Yu ZL: An ethanol extract of the rhizome of Atractylodes chinensis exerts anti-gastritis activities and inhibits Akt/NF- $\mathrm{BB}$ signaling. J Ethnopharmacol 228: 18-25, 2019.

24. Hossen MJ, Amin A, Fu XQ, Chou JY, Wu JY, Wang XQ, Chen YJ, Wu Y, Li J, Yin CL, et al: The anti-inflammatory effects of an ethanolic extract of the rhizome of Atractylodes lancea, involves Akt/NF- $\kappa \mathrm{B}$ signaling pathway inhibition. J Ethnopharmacol 277: 114183, 2021.

25. Zhu B, Zhang QL, Hua JW, Cheng WL and Qin LP: The traditional uses, phytochemistry, and pharmacology of Atractylodes macrocephala Koidz:: A review. J Ethnopharmacol 226: 143-167, 2018.

26. Wang $\mathrm{C}$, Duan $\mathrm{H}$ and He L: Inhibitory effect of atractylenolide I on angiogenesis in chronic inflammation in vivo and in vitro. Eur J Pharmacol 612: 143-152, 2009.

27. Guide for the Care and Use of Laboratory Animals. National Academies Press, Washington, DC, 1996.

28. Olfert ED, Cross BM and McWilliam AA (eds). Guide to the Care and Use of Experimental Animals. Vol 1. 2nd edition. Ottawa, ON, Canada, 1993.

29. Livak KJ and Schmittgen TD: Analysis of relative gene expression data using real-time quantitative PCR and the 2(-Delta Delta C(T)) method. Methods 25: 402-408, 2001. 
30. Al-Awar A, Kupai K, Veszelka M, Szúcs G, Attieh Z, Murlasits Z, Török S, Pósa A and Varga C: Experimental diabetes mellitus in different animal models. J Diabetes Res 2016: 9051426, 2016.

31. Da Silva LM, da Silva RCMVAF, Maria-Ferreira D, Beltrame OC, da Silva-Santos JE and Werner MFP: Vitamin C improves gastroparesis in diabetic rats: Effects on gastric contractile responses and oxidative stress. Dig Dis Sci 62: 2338-2347, 2017.

32. Li J, Tang HL, Chen Y, Fan Q, Shao YT, Jia M, Wang JC and Yang CM: Malondialdehyde and SOD-induced changes of gastric tissues in acute gastric mucosal injury under positive acceleration. Genet Mol Res 14: 4361-4368, 2015.

33. Bharucha AE, Batey-Schaefer B, Cleary PA, Murray JA, Cowie C, Lorenzi G, Driscoll M, Harth J, Larkin M, Christofi M, et al; Diabetes control and complications trial-epidemiology of diabetes interventions and complications research group: delayed gastric emptying is associated with early and long-term hyperglycemia in type 1 diabetes mellitus. Gastroenterology 149: 330-339, 2015.

34. Yamamoto T, Watabe K, Nakahara M, Ogiyama H, Kiyohara T, Tsutsui S, Tamura S, Shinomura Y and Hayashi N: Disturbed gastrointestinal motility and decreased interstitial cells of Cajal in diabetic db/db mice. J Gastroenterol Hepatol 23: 660-667, 2008 .
35. Chen W, Jiang C, Jin X, Shen W, Song B and Li L: Roles of stem cell factor on loss of interstitial cells of Cajal in bladder of diabetic rats. Urology 78: 1443.e1-1443.e6, 2011.

36. Yu Y, Cai Q and Jia TZ: Study on variation of gastroprotective effect of Atractylodes lancea Rhizome before and after processing. Zhong Yao Cai 39: 760-763, 2016 (In Chinese).

37. Giacco F and Brownlee M: Oxidative stress and diabetic complications. Circ Res 107: 1058-1070, 2010.

38. Xu L, Li Z, Guo F: Curcumin improves expression of ghrelin through attenuating oxidative stress in gastric tissues of streptozotocin-induced diabetic gastroparesis rats. Eur J Pharmacol 718: 219-225, 2013.

This work is licensed under a Creative Commons Attribution-NonCommercial-NoDerivatives 4.0 International (CC BY-NC-ND 4.0) License. 